\title{
PHASE ANALYSIS OF NICKEL SUPERALLOY INCONEL 738 LC
}

\begin{abstract}
Alloys of INCONEL (hereinafter IN) type play an important role among superalloys, used for the components of aircraft engines, gas turbines and turbo blowers. It is cast material which is alloyed in a complex manner on the Cr-Al-Mo-Ti-Nb-Zr basis.

The presented work made a detailed microstructural analysis of cast nickel superalloy IN 738 LC after heat treatment to the required quality and after long term annealing at the temperature of $850{ }^{\circ} \mathrm{C}$ and at dwell of 100, 500, 1000, 5000 and 10000 hours.

Higher level of alloying of this alloy shows the higher level of a segregation activity. This may lead to high temperature exploitation to the development of microsegregation processes, connected to possible precipitation of carbidic or some variants of intermetallic phases [1]. Several strengthening mechanisms take place here, and a main strengthening is the precipitation strengthening by coherent precipitates of an intermetallic phase $\mathrm{Ni}_{3} \mathrm{Al}$, or $\mathrm{Ni}_{3}(\mathrm{Ti}, \mathrm{Al})$ [2].

The objective of the presented microstructural analysis consisted in a more detailed understanding of investigated nickel superalloy from a technical applicability viewpoint.
\end{abstract}

\section{Introduction}

High requirements for materials working in extreme conditions create space for the use of nickel based superalloys. Superalloys are suitable for these demanding applications particularly due to the fact that they preserve almost unchanged strength even after long term exposition to the temperatures exceeding $650{ }^{\circ} \mathrm{C}$. The most exacting application of these materials is their use in heat parts of turbines. Important position of superalloys in this area is reflected in the fact that at present they represent more than 50\% of mass of advanced aircraft engines. Extensive use of superalloys in turbines, supported by the fact that thermo dynamic efficiency of turbines increases with increasing temperatures at the turbine inlet, became a partial reason for the effort aimed at increase of maximum utility temperature of high alloyed alloys $[3,4]$.

This increase was enabled namely by two factors. The first factor consists in advanced processing techniques, which improved purity of alloys and thus increased its reliability, and also in mastering of a directional crystallisation technique and subsequently in mastering of technology of single crystalline products manufacture. The second factor consists in development of alloys with higher utility temperature, particularly by alloying with Re, W, Ta and Mo [4].

The submitted paper is oriented on materials engineering investigation of microstructural characteristics of cast nickel superalloy IN $738 \mathrm{LC}$ after heat treatment to the required quality and after long term annealing at the temperature of $850{ }^{\circ} \mathrm{C}$ within interval of $100-10000$ hours.

\section{Material and Experimental Technology}

The microstructural analysis was made with the use of samples of the above mentioned nickel superalloy IN 738 LC. The analysis was made on the sample in the initial state after annealing to required quality by the mode $1120{ }^{\circ} \mathrm{C} / 2 \mathrm{~h} / \mathrm{air}+845^{\circ} \mathrm{C} / 24 \mathrm{~h} / \mathrm{air}$, and subsequently on the samples after long term annealing at the temperature of $850{ }^{\circ} \mathrm{C}$ for $100,500,1000,5000$ and 10000 hours. Microstructure was developed by chemical etching and it was documented on light metallographic microscope GX51.

Electron-microscopic investigation of the investigated alloy was made on a scanning electron microscope JEOL JSM-6490LV equipped with an energy dispersive spectral analyser INCA $\mathrm{x}$ act. Documentation of microstructure was made in the mode of secondary electrons (SEI) and backscattered electrons (COMPOmaterial contrast). Individual phases were identified by qualitative $\mathrm{X}$-ray microanalysis. The semiquantitative X-ray microanalysis was made only in the case of particles greater than $1 \mu \mathrm{m}$ when results were not distorted more significantly by $\mathrm{X}$ ray signal from the surrounding matrix.

The following Table I contains a chemical composition of the investigated alloy.

For this nickel superalloy additional information about chemical constitution is given - a mean value of an electron vacancy level on the $3 \mathrm{~d}$ sphere $\bar{N}_{V}=2.36$ max. On the basis of this value it is possible to state in conformity with the existing experience that the investigated alloy will probably not show a susceptibility

\footnotetext{
* Zdenek Jonsta, Petr Jonsta, Katerina Konecna, Miriam Gabcova

Department of Materials Engineering, Faculty of Metallurgy and Materials Engineering, VSB-Technical University of Ostrava, Czech Republic, E-mail: zdenek.jonsta@vsb.cz
} 


\begin{tabular}{|c|c|c|c|c|c|c|c|c|c|}
\hline $\mathrm{C}$ & $\mathrm{Cr}$ & $\mathrm{Ti}$ & $\mathrm{Al}$ & $\mathrm{Fe}(\max )$ & $\mathrm{Nb}$ & $\mathrm{Ta}$ & $\mathrm{Co}$ & $\mathrm{Zr}$ & $\mathrm{Ni}$ \\
\hline 0.09 & 15.7 & 3.20 & 3.20 & & 0.60 & 1.50 & 8.00 & 0.03 & \\
- & - & - & - & 0.35 & - & - & - & - & rest \\
0.13 & 16.3 & 3.70 & 3.70 & & 1.10 & 2.00 & 9.00 & 0.08 & \\
\hline
\end{tabular}

to the formation of $\sigma$ - phase. It was found in practice that $\sigma-$ phase was formed on the one hand only in a case that $\bar{N}_{V}>2.5-$ 2.6, on the other hand in a case when $\bar{N}_{V} \approx 2.0-2.1$.

\section{Basic microstructural analysis}

The basic microstructure of the sample in an initial state was formed by $\gamma$ matrix. Particles of $\gamma^{\prime}$ phase were segregated in it. Two stage heat treatment led to the creation of bimodal distribution of this phase. Chemical composition of particles of the $\gamma^{\prime}$ phase with certain variability corresponds to intermetallics $\mathrm{Ni}_{3}(\mathrm{Al}$, Ti). This phase contained also significant quantity of dissolved Ta.
Processes of unmixing in the course of crystallisation led to the creation of distinct chemical heterogenities in the final microstructure. Primary carbides of the type MC were segregated in a non homogenous manner in the matrix. They contained variable quantities of strong carbide forming elements, namely tantalum, niobium and titanium. Carbides of the type MC often decorated grain boundaries. Numerous eutectic formations $\gamma+\gamma^{\prime}$ were segregated in interdendritic spaces. In the areas of eutectics that solidified as the last ones, coarse particles of the phase $\gamma^{\prime}$ were formed. In some cases small shrinkage porosities were present in their vicinity and a phase rich in $\mathrm{Zr}$ was also present locally. EDX spectrum showed that it was probably $\mathrm{ZrS}_{\mathrm{x}}$. Titanium carbonitrides were also detected in the proximity of eutectics. No particles of other

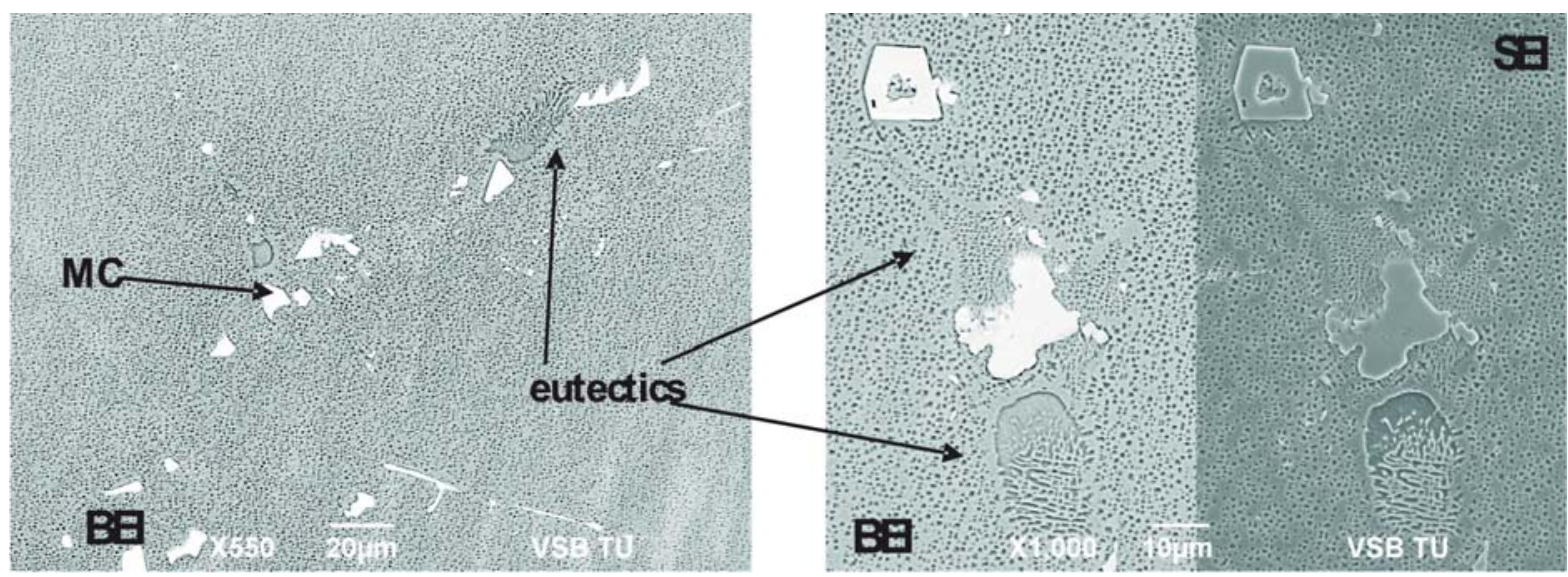

a) Eutectics and MC carbides in interdendritic spaces

b) Examples of eutectics and MC carbides in their proximity

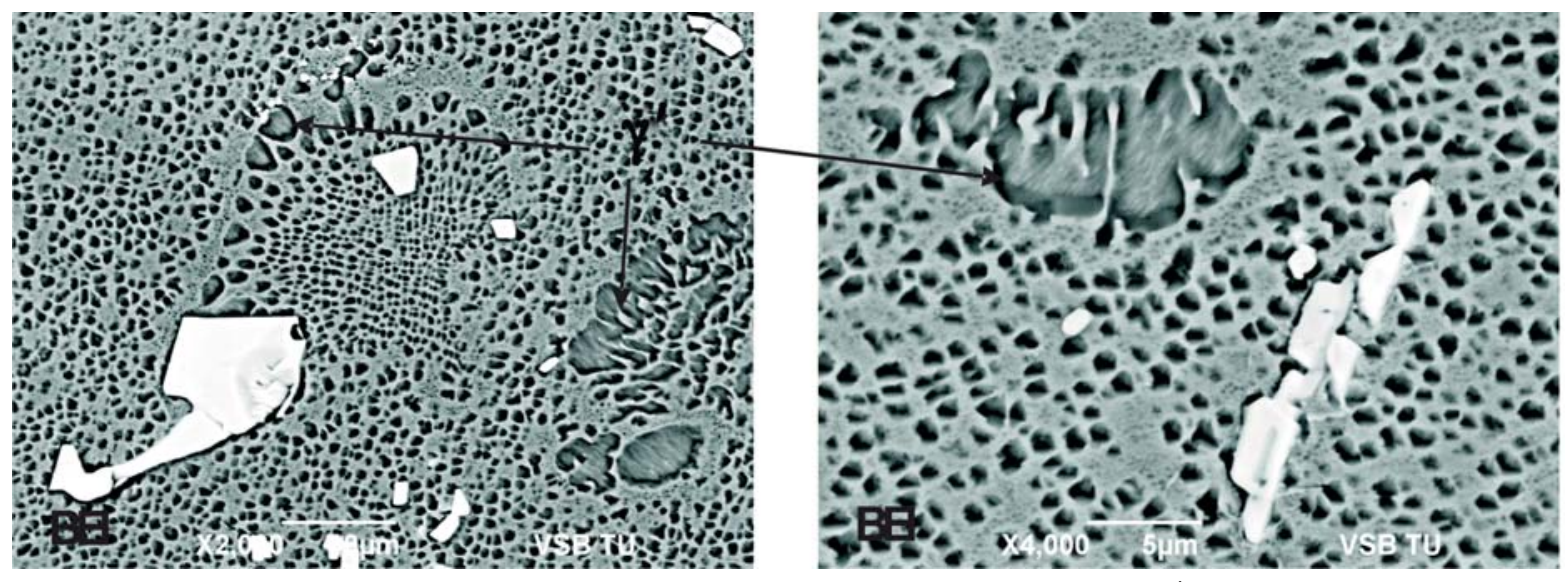

c) Detail of eutectics

d) Detail of coarse particle $\gamma^{\prime}$, particle rich in Zr surrounded

by $M C$ carbides

Fig.1 Examples of structure in initial state 


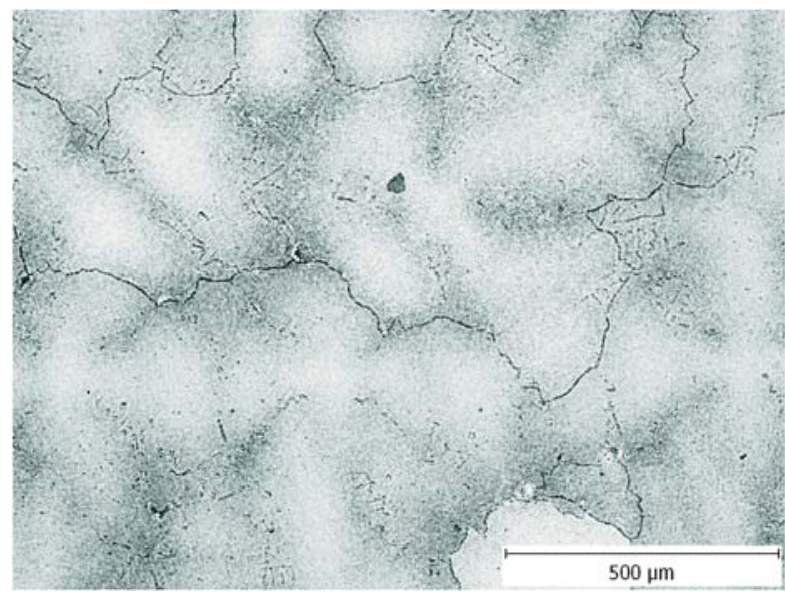

Fig. 2 Microstructure in initial state

minority phases with size exceeding approx. $0.5 \mu \mathrm{m}$ were observed. Fig. 1 documents the appropriate microstructure. At visualisation in backscattered electrons (BEI) the white contrast corresponds to primary $\mathrm{MC}$ carbides, particles $\mathrm{ZrS}_{\mathrm{x}}$ are grey.

It is evident from the next Fig. 2 taken with the use of a light microscope that dendritic structure in the initial state was not very distinct. During subsequent long term exposition at the temperature of $850{ }^{\circ} \mathrm{C}$ the bimodal distribution of the phase $\gamma^{\prime}$ in the total volume of the alloy is gradually eliminated [1]. In comparison with the initial state the dendritic structure was very distinct, as it can be seen in Fig. 3, documenting microstructure of the sample after long term annealing at the temperature of $850^{\circ} \mathrm{C} / 5000$ hours.

\section{Microstructural characteristics after long term annealing}

After long term annealing differences were observed in a grain size in interdendritic spaces and inside branches of dendrites. Particles in interdendritic spaces were coarser, inside branches of den-

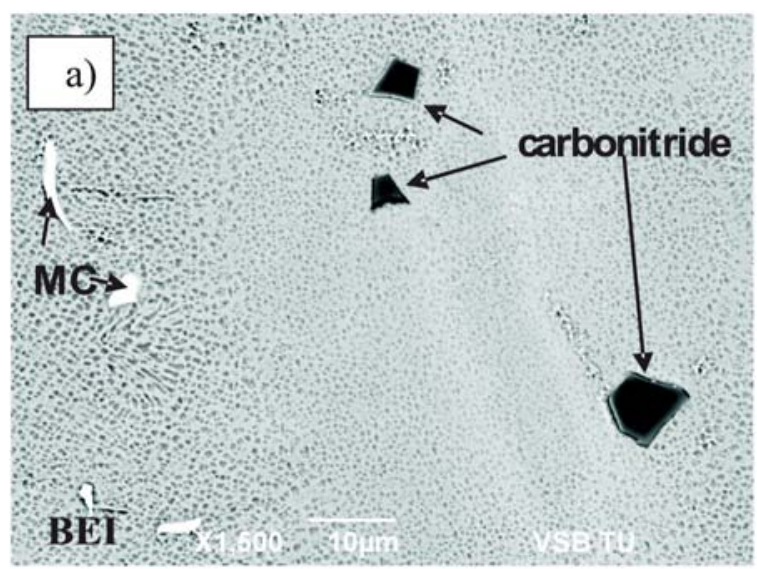

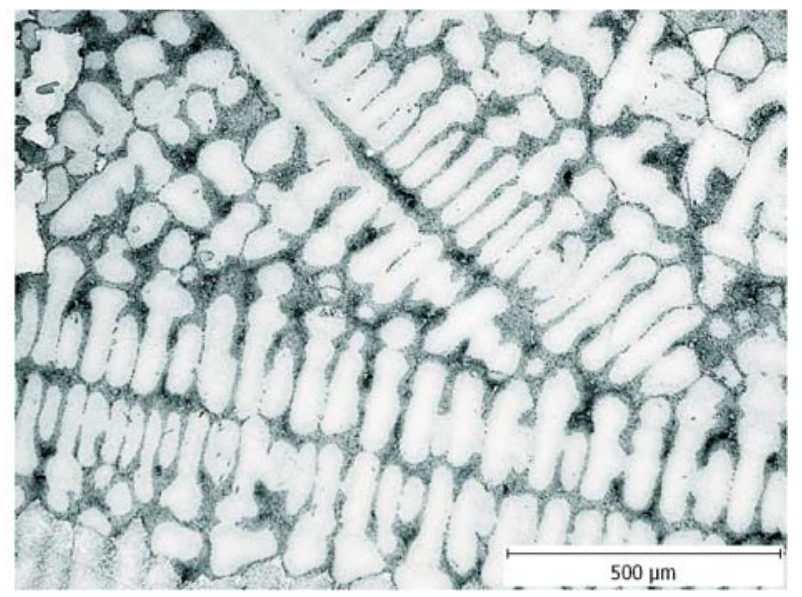

Fig. 3 Microstructure after annealing $850^{\circ} \mathrm{C} / 5000$ hours

drites were finer. Grain boundaries were decorated with discontinuous mesh of carbides $\mathrm{MC}$ and $\mathrm{M}_{23} \mathrm{C}_{6}$. It is known that primary carbides in nickel superalloys are unstable. They gradually decompose at high temperatures.

This decomposition is accompanied with the creation of secondary carbides particles $\mathrm{M}_{23} \mathrm{C}_{6}$ and phase $\gamma^{\prime}$ [2]. It is evident from photos of microstructures in Figs. $4 a, 4 b$ and 5 that the creation of secondary carbides occurs both by degeneration of primary $\mathrm{MC}$ carbides, and by precipitation from solution, which contains residual carbon. A rim formed by $\gamma^{\prime}$ phase was gradually formed along carbides on grain boundaries. It was the most distinct in the sample with the longest duration of annealing (10 000 hours). This example is shown in Fig. 6.

Formations of eutectics were more difficult to be discerned with an increasing duration of annealing due to the growth and coarsening of particles of the $\gamma^{\prime}$ phase. Migration of grain boundaries occurred, the boundaries became significantly more toothed, which according to the work [6] is advantageous from the view-

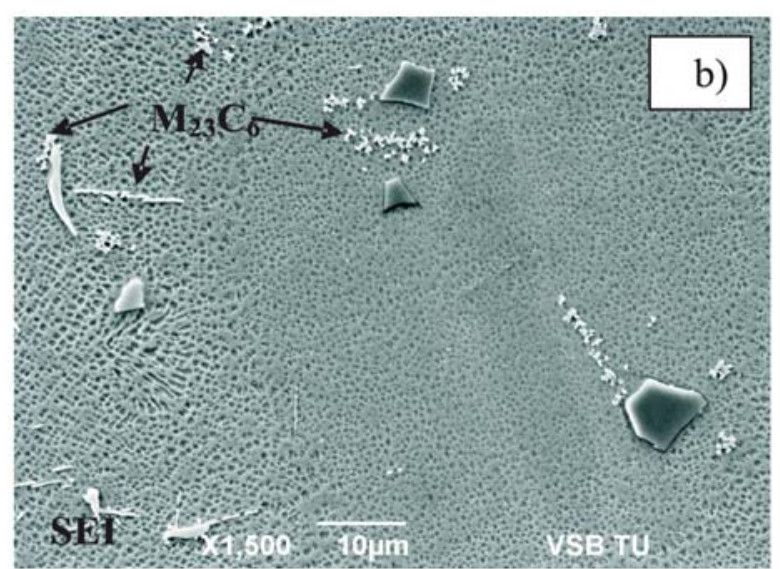

Fig. 4 An example of structure after annealing by regime 500 hours $/ 850{ }^{\circ} \mathrm{C}$ 


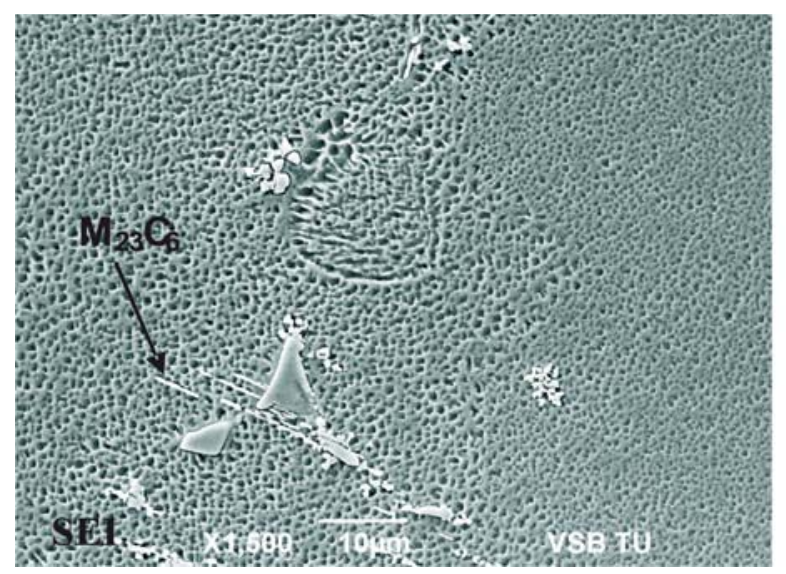

Fig. 5 Precipitation of $M_{23} C_{6}$ around $M C$ carbides and from $\gamma$ solution

point of resistance to creep. Fig. 7 shows examples of structures after annealing of 2000 hours at the temperature of $850{ }^{\circ} \mathrm{C}$.

With elongation of annealing duration at the temperature of $850^{\circ} \mathrm{C}$ growth and coarsening of the phases which were present in a structure occurred already after annealing at $850^{\circ} \mathrm{C} / 100$ hours. The phase rich in $\mathrm{Zr}$ was not anymore detected in the samples with duration of annealing since 2000 hours. After the longest duration of annealing (10 000 hours) morphology of $\gamma^{\prime}$ phase particles has changed. Particles became rounder, the difference between their size inside dendrites and in interdendritic spaces diminishes. $[3,5]$. Very important is the fact that no occurrence of TCP phases (for example $\sigma$ phase, $\mu$ phase, $\mathrm{R}$ phase) was found in any of investigated samples.

\section{Conclusions}

The presented paper presents a carried out detailed phase analysis of the samples of refractory nickel superalloy IN 738 LC both in its initial state and after heat treatment to the required

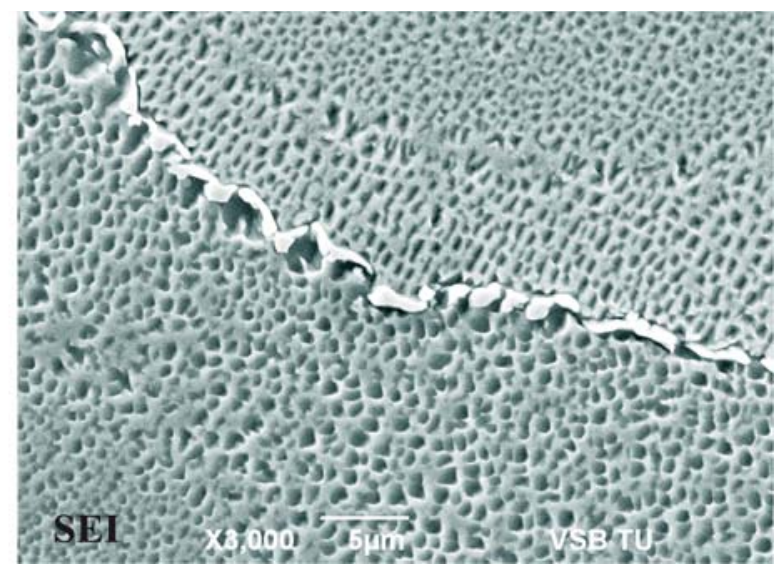

Fig. 6 Grain boundary decorated by particles $M_{23} C_{6}$ coated by $\gamma^{\prime}$ film

quality and after long-term annealing at the temperature of $850{ }^{\circ} \mathrm{C}$ with dwell in the interval from $10^{2}$ to $10^{4}$ hours.

It was possible to state on the basis of the obtained results that with increased duration of dwell at the temperature of $850{ }^{\circ} \mathrm{C}$ no precipitation of new minority phases occurred. Only processes of growth and coarsening of phases' particles which were present in the structure already after annealing at $850{ }^{\circ} \mathrm{C} / 100$ hours occurred. Morphology of particles of $\gamma^{\prime}$ phase in the basic matrix $\gamma$ also occurred as they coagulated and rounded off. This finding is in good correlation with the work [3].

Special attention was paid also to a possibility of undesirable TCP phases precipitation, particularly of the phase $\sigma$. Due to the value of concentration of vacancies on $3 \mathrm{~d}$ sphere, which was determined as $\bar{N}_{V} \approx 2.36$ max., precipitation of these undesirable phases appeared to be improbable. The microstructural analysis confirmed this assumption since these undesirable phases were not detected in any variant of a long term exposition at the temperature of $850{ }^{\circ} \mathrm{C}$.
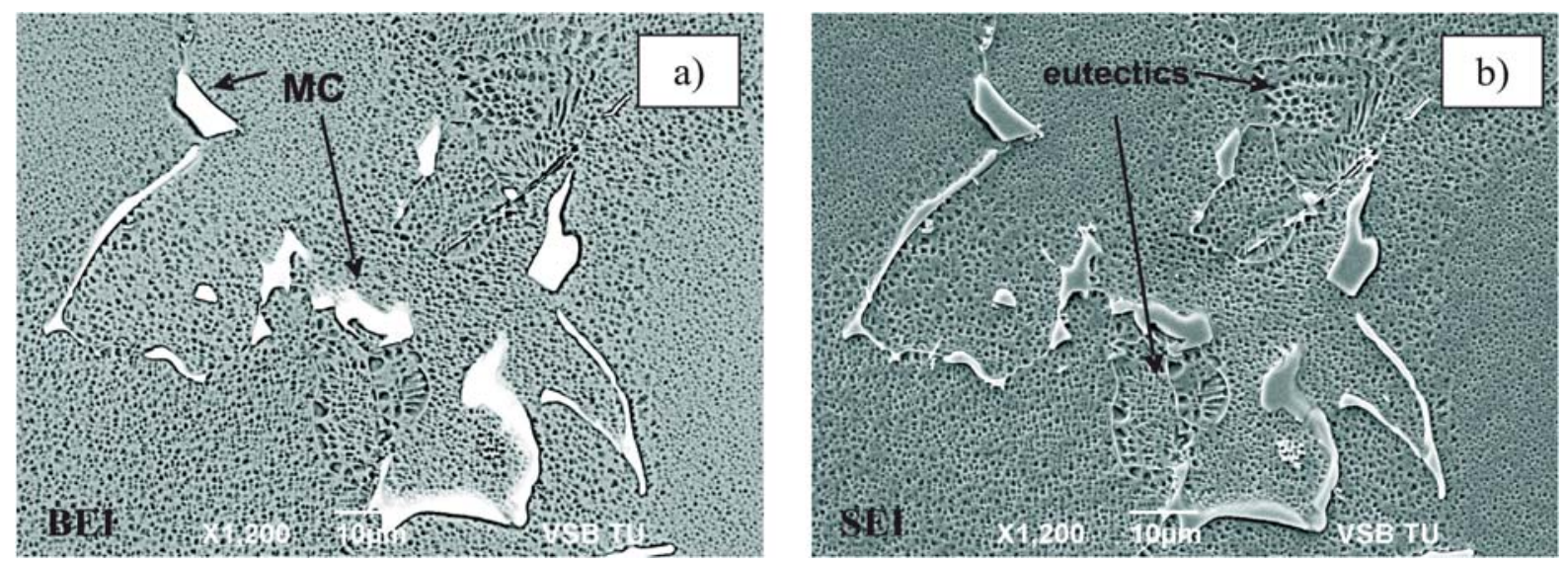

Fig. 7 Coarse MC carbides and indistinct eutectics 
The realised microstructural analysis showed that structural changes at long term annealing at the temperature of $850{ }^{\circ} \mathrm{C}$ were not noticeably unfavourable and that they did not cause degradation of the investigated alloy at a long term high temperature exposition.

The obtained results extend the findings and knowledge about investigated superalloy from the viewpoint of ensuring its operational reliability and safety.

\section{Acknowledgement}

The paper was prepared thanks to the financial support of the MSMT MSM 6198910013 and RMTVC CZ.1.05/2.1.00/01.0040 projects.

\section{References}

[1] MOSHTAGHIN, R., S., ASGARI, S.: Growth Kinetics of $\gamma^{\prime}$ Precipitates in Superalloy 738LC During Long Term Aging, In: Materials \& Design [online], Vol. 24, 5/ 2003, pp. 325-330, ISSN 0261-3069.

[2] EL-BAGOURY, N., WALY, M.,.NOFAL, A.: Effect of Various Heat Treatment Conditions on Microstructure of Cast Polycrystalline IN738LC Alloy, In: Materials Science and Engineering: $A$ [online], Vol. 487, Issues 1-2/2008, pp. 152-161, ISSN 0921-5093.

[3] HERNAS, A., JONSTA, Z., et. al.: Refractory Steels and Alloys (in Czech), VSB-TU Ostrava, 2nd Edition, 2010, 340 pp, ISBN 80968605-6-9.

[4] HRBACEK, K.: Research and Development of Technology of Precise Casting of Blades for Stationary Gas Turbines Enabling Substitution of Forged Blades by Cast Blades (in Czech), Research Report, Velka Bites, 2005, 40 pp.

[5] IDOWU, O., A., RICHARDS, N., L., CHATURVEDI, M., C.: Effect of Bonding Temperature on Isothermal Solidification Rate During Transient Liquid Phase Bonding of Inconel 738LC Superalloy, In: Materials Science and Engineering: A [online], Vol. 397, 1-2/ 2005, pp. 98-112, ISSN 0921-5093.

[6] WISNIEWSKI, A., BEDDOES, J.: Influence of Grain-Boundary Morphology on Creep of a Wrought Ni-base Superalloy, In: Materials Science and Engineering: A [online], Vol. 510-511, 2009, pp. 266-272, ISSN 0921-5093. 